\title{
Study on the Application of Goal-Setting Theory in University Sports Teaching
}

\author{
Gong Fenghua \\ Nantong University, Nantong, China
}

\begin{abstract}
The continuous development of education makes it necessary to effectively upgrade the teaching theory and change the teaching structure in the actual establishment and implementation of teaching projects for the purpose of realizing the overall teaching goals. The goal-setting theory has gained much popularity in recent years, which is mainly about the establishment of effective development and negotiation of individual behavior to promote the establishment and operation of the set goals. The paper mainly analyzed the connotations of goal-setting theory in universities sports teaching and launched a detailed discussion on the problems appeared in the combination of actual basic goal-setting theory with universities sports teaching. And the writer put forward corresponding views on practical measures for current education situation, aiming to offer better support to the goal-setting theory in universities to enhance the overall teaching quality of the school sports teaching.
\end{abstract}

Keywords: goal-setting theory, university, sports teaching, application

\section{Connotations of Operational Goal-setting Theory in University Sports Teaching} \section{Building Effective Teaching Goals}

For establishment and improvement of any of the teaching process, the most basic requirement is setting up corresponding teaching goals to ensure that the overall teaching structure is more targeted and offer better help to teachers and students in forming effective teaching interaction. And this is where the goal-setting theory which is more targeted comes form. According to sports psychology, we can draw the conclusion that, in the process of goal setting, we should effectively classify the target types, so as to keep the teaching behavior effective. The actual goals in sports teaching can be classified into grade goal, performance goal and process goal which are an unity with respective characteristics. Among these three goals, grade goal focuses on final results secured in games or actual teaching behavior, which requires comparison among students; performance goal emphasizes students' individual behavior standard in actual teaching process relative to the other students, which focuses on results coming from competition and comparison; and process goal is the most dynamic one, attaching importance to students' learning behavior standard in the whole process, which requires effective analysis.

\section{Building the Performance Evaluation for the Corresponding Goals}

In actual teaching process, it is necessary to set certain standards for performance appraisal of the goals to ensure that new corresponding goals can be effectively implemented and realized, which is mainly about

Gong Fenghua, Master, lecturer, Sports Sociology and Humanities, Institute of Sports Science, Nantong University. 
whether the corresponding target can be reached, how much efforts are required in such a process and what influences can be produced and how long it can be remained after achieving the goals. In addition, in the process of performance appraisal for goals, the relevant teaching staff should focus on the corresponding assessment mechanism which includes the following four aspects:

1. To ensure that the goal can attract attention and guide students to make efforts for the whole goal, and avoid unnecessary behavior deviating from the goal;

2. To ensure that the corresponding efforts are in direct proportion of the goal so as to build an effective act direction;

3. To ensure the timeliness of the goal-setting, which can keep whole targeted behavior long;

4. The process of goal-setting can effectively arouse students' learning behavior and ensure their effective use of overall knowledge and strategies, which can actually improve the performance value of the whole goal (Chen et al. 2015).

\section{Building the Corresponding Principles for the Targets}

When setting the corresponding learning goals, the relevant personnel should have standard classification in accordance with the appropriate setting rules, so that the overall project can be practiced effectively ( $\mathrm{Yu}$, 2015). In the goal-setting, the main principles includes:

1. The goal must be real, effective, and accessible to be observed and measured;

2. The goal in setting process must meet the time limit, that is, timeliness;

3. The goal should not be too difficult to achieve, and medium difficulty is the best choice;

4. When sitting the goal, the relevant management personnel should, in accordance with the types of teaching goals, ensure that the process goal, performance goal, and grade goal are fully integrated;

5. The relevant management personnel should keep a record of the completion of the actual teaching goals and systemize the corresponding development of the progress;

6. Relevant teaching staff should make full use of short-term goals to realize long-term goals;

7. In the actual teaching, the training goal and the competitive goal should be fully integrated;

8. The students must fully understand the contents of corresponding goals;

9. Individual differences of students should be fully considered in practical teaching.

Moreover, the widely used method for goals summary now is SMART principle, of which S represents Special, meaning that the specific behavior must be guided in the process of goal-setting; $M$ stands for Measurable, showing that the relevant goal can be actually measured. A refers to Action-oriented, suggesting that the relevant goal must have a clear task direction; $\mathrm{R}$ is equal to Realistic, that is, the corresponding goals should have actual effect; and T represents Timely—the task should have timeliness (Luo et al., 2016).

\section{Problems in the Integration of Goal-Setting Theory and the University Sports Teaching}

\section{Feasibility and Evaluability}

When establishing the corresponding teaching goals, an effective interaction should be achieved between teachers and students to ensure that teachers can have real-time understanding of the student learning dynamics, and establish related teaching projects and goals the first time in the light with the actual reaction of the students. And teachers should set effective and targeted goals for students and regulate the goal's direction and focus according to actual sports exercise. In addition, teachers should build effective evaluation mechanism for 
the corresponding behavior (Luo, 2015). What is more, the relevant personnel should keep the actual goal-setting scientific and rationale and ensure that the projects have actual effect and are evaluable in the realization of these goals. In other words, the goals should provide guidance for students to unleash their learning potential so that students have the incentives to do further study; and can improve students' ways of self motivation to ensure the effective practice of sports teaching with the help of these goals, thus achieving the actual teaching effect. Teachers should also ensure that teaching goals conform to students' individual development, thus setting students-oriented teaching goals and helping students to achieve these goals successfully (Tan, 2015).

\section{Comprehensiveness}

When setting the teaching goals, teachers should establish both long-term goals and short-term goals. Among them, the long-term goal for modern sports teaching, which requires the upgrade of students' comprehensive qualities, should ensure that students can regulate their own behavior in line with the corresponding standards within a period of time. Long-term goal has a clear record of students' physical fitness and overall qualities. Besides, teachers should set phased goals which can enable students to make improvements within a period of time. Teachers should establish personalized goals and evaluation standards basing on students' actual situation and timely solve problems they encountered in realizing the phased goals by providing them necessary teaching guidance, thus improving the whole teaching quality. In the actual teaching process, teachers should combine the long-term goals with short-term goals and establish effective evaluation standard for the maneuverability of short-term goals, which can upgrade timely to suit the students' actual situation (Jin, 2015).

\section{Fuzzy Goals and Precise Targets}

In the actual process of teaching, teachers should set effective fuzzy goals and precise targets to improve students' learning interest. To set a precise target, teachers should analyze the data of teaching content before establishing effective tasks to make the overall goal feasible. When setting a fuzzy goal, relevant teaching staff should deal with the corresponding problems although it is impossible to analyze the actual data of the fuzzy goal. The short-term goal must be precise.

\section{Achievable Goals and Unachievable Goals}

In actual sports teaching, an achievable goal is equal to a more intuitive teaching goal which can be realized by students through their learning behavior. And such a goal is set according to students' abilities and suits their personal qualities, which has no size standard. On the contrary, unachievable goals are more abstract ones, most of which are unrealistic even if students use corresponding methods. However, when setting an achievable goal, teachers should take differences among students into full consideration to establish an effective learning goal mechanism (Liu, 2014).

When setting an achievable goal, teachers should have an effective analysis of students' actual situation. Only when the goal is close to students' actual situation can they recognize it and make further efforts to achieve it. Unachievable goals, however, will reduce students' enthusiasm for learning, which means that teachers should classify those unachievable goals and strengthen the right value orientation to reduce the numbers of those goals (Nie, 2016).

\section{Directionality}

In the actual teaching process, teachers should pay attention to students' actual situation, and effectively 
manage their physical abilities and basic physical qualities by virtue of directive goals, effectively improving their basic physical qualities. And, in the process of setting directive goals, teachers should have a clear understanding that the goals should link to the students' efforts to ensure certain direction. Only through unleashing students' potential and enthusiasm for learning can students make further efforts in sport learning.

In actual goal orientation, teachers should set incentive teaching goals and compare the directive goals longitudinally at the first time, through which shows different advantages and problems of students. Only when the evaluation mechanism of the goals conform to students' actual situation, can it truly improves students' personal ability. And in the completion of directive goals, teachers should attach importance to reviewing students' efforts instead of evaluating the students' actual performance, which can provide better help for students to build confidence. The setting of directive goals with practical value should be in line with the practical demand.

\section{Analysis of the Application of Goal-Setting Theory in University Sports Teaching}

\section{Making the Goals Feasible}

In the process of university sports teaching, the teaching behavior can be adjusted effectively by using the goal-setting theory. From psychology, we can know that the corresponding goal plays a role in promoting social progress and people's actual behavior (Chen, 2014). Setting goals can inspire students' potential. Teachers should provide guidance for students' behavior by teaching goals and present the focus of the goals, so that students can master relevant evaluation mechanism and standard while learning. By guiding students with goals in actual teaching, teachers can improve students' self-motivation effect and enable them to finish tasks efficiently. In the process of sports teaching, sports teachers should classify students' actual situation by using relevant goals and build effective project analysis mechanism basing on students' actual demands and skills. For example, in actual goal-setting, teachers should conduct reasonable analysis of students physical functions, and only when students realize the teaching goals, can teachers obtain actual value of setting teaching goals.

\section{Integrating Various Goal Structures}

In the actual teaching process, the teacher should take goal integration mechanism into full operation so that those goals can be effectively integrated, thus obtaining the best teaching results. Firstly, teachers should integrate the long-term goals with short-term goals. They should focus on training students' comprehensive sports qualities and set effective long-term goal. To ensure that students can build goal-oriented behavior, teachers should divide these long-term goals into achievable short-term goals (Hang \& $\mathrm{Gu}, 2013$ ). When building integrated goal-management mechanism, teachers should focus on the improvements of students' actual abilities and qualities and enable students to gain experience from teaching goals. And students can also enhance their confidence and become more interested in study after realizing the goals (Cui, 2015).

Secondly, teachers should integrate the precise goals with fuzzy goals. When establishing and developing actual teaching activities, teachers should pay attention to students' learning ability to establish clear and feasible teaching goals. This process aims to set precise goal because of data collection. In the process of setting a precise goal, teachers can timely establish effective interactions and communications with students, which can maximize the motivation of the goal. Although fuzzy goal can provide some guidance, it has fewer influences in motivating students' potential. 
Thirdly, teachers should combine the achievable goals with unachievable goals. In the actual teaching process, teachers should pay attention to achievable goals and help students to realize their teaching goals through their own efforts, so as to take teaching contents into practice. And teachers should guide students to establish effective behavior evaluation mechanism. With self-confidence in learning, students can better respond to the teaching challenges and continue to learn and absorb relevant knowledge and skills. Teachers should effectively stimulate students' learning potential in setting achievable goals, and establish the behavior index with the theory developed recently. And they should try to minimize the unrealistic goals with difficulties to protect students' self-confidence in learning.

Finally, the teacher should focus on the integration of evaluation mechanism for the directive goals in actual teaching process. The teaching goals must have efficiency which can reflect students' practical ability in some degree, so that teachers can have a direct understanding of students' ability of learning relevant knowledge and skills through the degree of completion. Teachers should pay special attention to students' efforts instead of excessively depending on their learning results (Li, 2012). They should encourage students to check their efforts longitudinally and make greater efforts to achieve teaching goals accordingly, thus fundamentally upgrading their overall learning and practical abilities.

In addition, teachers should establish plans according to directional indicators in the actual teaching process. They can encourage students to set their own goals and guide them to build their own evaluation mechanism, through which students can make efforts to realize their goals. Also, they should have students clearly recognized their improvements which meet their own advantages in sports grades and abilities. Much attention should also be paid to students' efforts which can ensure their progress of personal abilities. When setting qualitative and quantitative objectives, teachers should focus on students' learning behavior to establish corresponding evaluation mechanism.

\section{Ensuring Timely Feedback of Students' Learning Situation}

There is always lack of communications and interactions between teachers and students in sports teaching. So, teachers should improve this situation with goal-setting theory through the ways including the optimization of the teaching indicators, the collection and summary of students' practical learning results and the effective discussion of the students' problems. Teachers should set targeted teaching goals after having a real understanding of the students' sports learning demands. What is more, teachers should give students a fair evaluation for their progress in learning abilities, so that they can further optimize their learning behavior after receiving these feedback. Teachers also have to timely correct students' learning behavior through interactions, giving them professional advice, thus realizing the real quality optimization (Zhu \& Yan, 2014).

In addition, through teacher-student interaction and feedback, teachers can have a clear understanding of the completion of students learning goal and analyze their results, from which teachers can draw the corresponding teaching conclusions. After collecting the feedback, teachers will concentrate on collecting the goal-setting situation according to the corresponding opinions. Teachers should evaluate students' performance in the actual teaching process and give them appropriate encouragement, so that they can achieve the phased goal successfully. In the establishment of assessment methods, teachers should analyze and evaluate students' sports ability so as to establish effective project feedback. The improvement of students practical ability requires timely supervision and management of the teaching behavior. 


\section{Conclusion}

To sum up, in the promoting of the goal-setting theory, teachers should make a thorough research on the principle of the goal and establish evaluation criteria accordingly. The ultimate aim of university sports teaching is to upgrade students' physical quality and consciousness through the physical exercises, so only when students' basic physique is enhanced, can they develop in an all-round way. The goal-setting theory is created for the better practice of the teaching goals and strategies. In a word, teachers should use goal-setting theory in a reasonable way and build effective learning interactions with students, which can really promote the sustainable development of students' sports abilities and qualities.

\section{References}

Chen, S. L. (2014). Analysis on the application of goal-setting theory in university taijiquan teaching. Harbin: Contemporary Sports Technology, 4(25), 134-135.

Chen, W., Zhou, X. C., Liu, J. et al. (2015). Study on personalized online learning models basing on goal-setting theory. Chongqing: Southwest China Normal University Journal (Natural Science Edition), 44(4), 165-169.

Cui, Y. M. (2015). Study on the application of goal-setting theory in football passing skill teaching. Harbin: Contemporary Sports Technology, 5(36), 164-165.

Hang, H. B., \& Gu, P. (2013). Views on the application effects of goal orientation theory \& goal-setting theory in table-tennis teaching. Jiamusi: Journal of Jiamusi Education Institute, 11(11), 418-419.

Jin, L. Z. (2015). Analysis of the application of goal orientation theory \& goal-setting theory in table-tennis teaching. Changchun: Intelligence, 10(10), 225.

Li, R. (2012). Study on incentive problem of university students cadre - basing on goal-setting theory \& goal management theory. Wuhan: Contemporary Economics, 10(10), 140-141.

Liu, J. (2014). Analysis on the practical application of goal-setting theory in sports teaching. Hohhot: Course Education Research (New Teacher Teaching Edition), 30(30), 191.

Luo, Z., Cui, A., Tang, M. et al. (2016). The application of nursing intervention in intracranial implantation of vegetative patients basing on the goal-setting theory. Haiku: Hainan Medical Journal, 27(4), 686-688.

Luo, D. X. (2015). Study on the application of goal-setting theory in university taijiquan teaching. Zhengzhou: Human Resources Development, 14(14), 153-154.

Nie, Y. F. (2016). Study on the roles of goal-setting theory and implementation intentions in motivating vocational college students. Tianjin: Journal of Tianjin Sino-German Vocational Technical College, 11(1), 86-89.

Tan, B. (2015). Study on football teaching strategy basing on goal-setting theory. Beijing: Bulletin of Sport Science \& Technology, $23(12), 86 \& 94$.

Yu, R. (2015). On the application of goal-setting theory in university table-tennis teaching. Xinjiang: Sports Time, 18(18), 164-165.

Zhu, X. J., \& Yan, J. (2014). Influential factors of the application of goal-setting theory in middle school sports teaching. Harbin: Contemporary Sports Technology, 33(33), 118-120. 